\title{
Cross-Validation Estimation for Frequency-Dependent I/Q Imbalance in MIMO-OFDM Receivers
}

\author{
Wei-Chi Lai • Ta-Yang Juan • Terng-Yin Hsu • \\ Sheng-Lun Chiou
}

Received: 4 March 2008 /Revised: 4 August 2009 / Accepted: 6 August 2009 /Published online: 8 September 2009

(C) 2009 Springer Science + Business Media, LLC. Manufactured in the United States

\begin{abstract}
The effects of variation in RF, such as $\mathrm{I} / \mathrm{Q}$ imbalance and filter mismatch, are extremely important for OFDM wireless accesses. This work presents a lowcomputational estimation of I/Q imbalances with filter mismatches to improve performance in MIMO-OFDM receivers. For $\mathrm{N} \times \mathrm{N}$ MIMO-OFDM systems, the proposed cross-validation estimation is such that, only $\mathrm{N}+1$ preambles are required to extract the mismatches of filters, gains and phases. With the estimated parameters, frequency-domain filters are exploited to correct frequency-dependent I/Q imbalances. Through performance evaluation of a $2 \times 2$ MIMO-OFDM system, with ideal channel estimations this study incurs a SNR loss of $1-1.2 \mathrm{~dB}$ to maintain a $10 \%$ PER at 1 - $\mathrm{dB}$ gain error, $10^{\circ}$-phase error and the worst $180^{\circ}$-filter mismatch. In addition, this algorithm is well-matched to IEEE 802.11n and new specifications discussed in IEEE 802.11 VHT study group.
\end{abstract}

Keywords Filter mismatch · I/Q imbalance - Cross validation $\cdot$ Frequency-Dependent Imbalance (FDI) . MIMO-OFDM

\footnotetext{
W.-C. Lai $(\square) \cdot$ T.-Y. Juan · T.-Y. Hsu

Department of Computer Science, National Chiao Tung University,

1001, University Road,

Hsinchu 300 Taiwan, Republic of China

e-mail: wclai@cs.nctu.edu.tw

T.-Y. Hsu

e-mail: tyhsu@cs.nctu.edu.tw

\section{S.-L. Chiou}

Institute for Information Industry,

Taipei, Taiwan, Republic of China

e-mail: richard.chiou@nmi.iii.org.tw
}

\section{Introduction}

Multiple-input multiple-output orthogonal frequency division multiplexing (MIMO OFDM) is widely used for nextgeneration communications over frequency-selective fading $[1,2]$. With the help of multiple transmitted antennas, multiple received antennas and special spatial formats, data accesses can be faster and more efficient than single-input single-output (SISO) systems. Unfortunately, RF distortions will cause serious degradations of performance in most OFDM-based designs. The key impacts are: the gain and phase mismatch between in-phase (I) and quadrature-phase (Q), namely I/Q imbalance; and a filter mismatch between I and $\mathrm{Q}$ denoted by frequency-dependent imbalance (FDI). In practice, the simultaneous occurrence of $\mathrm{I} / \mathrm{Q}$ imbalance and filter mismatch significantly degrades the system performance. Several schemes for OFDM systems have been proposed to handle I/Q imbalance [3-7]. These schemes can be categorized as follows.

1) Data-aided (DA) methods, in which special pilots and training symbols are inserted into the transmitted data $[3,4]$.

2) Nondata-aided (NDA) methods, in which the transmitted data are used without any other additional information $[5,6]$.

3) Adaptive FIR filter based methods, in which the received data before the FFT are utilized to handle estimation, were presented to certify for an Image Rejection Ratio (IRR) of 75-97 dB after compensation. [7].

Some blind I/Q imbalance estimators that rely on signal statistics have also been adopted to achieve estimation and compensation [8]. Although these methods can work well under I/Q imbalance, filter mismatches were less addressed and a lot of cycles were required for processes. Therefore, 
introducing the filter mismatch phenomenon into the system increases the estimation error. The I/Q imbalance with filter mismatch, namely frequency-dependent I/Q imbalance, is much critical for OFDM direct-conversion receivers to make the corresponding estimation and compensation be extremely difficult $[3,9]$.

To ensure that MIMO-OFDM wireless accesses function at frequency-dependent I/Q imbalances, this study presents a novel method to extract the useful properties of preambles to reduce the converged cycles. As a result, the interleaving arrangement of preambles can be utilized, namely cross validation, to estimate frequency-dependent I/Q imbalances for $\mathrm{N} \times \mathrm{N}$ MIMO-OFDM systems within $\mathrm{N}+1$ preambles. Then a frequency-domain (FD) filter is programmed by the estimated parameters to remove these I/Q distortions in each received antenna. Simulations of a $2 \times 2$ MIMOOFDM system indicate that the proposed approach results in a 1.2-dB SNR loss with ideal channel estimations to achieve 50-dB IRR and 8\% PER at frequency-dependent I/ $\mathrm{Q}$ imbalance with a gain error of $1 \mathrm{~dB}$, a phase error of $10^{\circ}$ and the worst FDI of $180^{\circ}$ [3]. Although 50-dB IRR with a SNR loss of $1-1.2 \mathrm{~dB}$ is not excellent, it is adequate to make systems work properly. Besides, the preamble-based solution is easily compatible with IEEE 802.11n [10] and next-generation wireless LAN discussed in IEEE 802.11 Very High Throughput (VHT) study group.

The rest of this paper is structured as follows. Section II addresses I/Q model and problem statement. Section III presents the proposed algorithm and architectures of estimation and compensation for frequency-dependent I/Q imbalances. The simulations and measurements are discussed in Section IV. Finally section V gives conclusions.

\section{System Assumptions}

\subsection{Packet Format}

Each MIMO-OFDM symbol has 64 sub-carriers that 56 subcarriers are data and 8 sub-carriers are nulls. The time-domain signal is preceded by the guard interval containing the last 16 samples of the OFDM symbol in every antenna. The packets are assumed to contain the common preambles (CP) and the MIMO preambles (MP) that CPs are all the same to every antenna, like the preambles of SISO-OFDM systems. Both CP and MP include two types: (1) short preambles and (2) long preambles, as illustrated in Fig. 1. The common short preambles (CSP) can be applied for packet detection and coarse synchronization, and the common long preamble (CLP), being real number, can be used for fine synchronization. The MIMO short preambles (MSP) are exploited for antenna calibrations, and all MIMO long preambles (MLP) are tone interleaved across transmitted antennas for channel estimations. The number of MLPs is equal to the number of transmitted antennas. Its valid length is equal to the number of data sub-carriers. In addition, the field of "Packet Type" records the number of antennas, a coding rate of FEC and modulation of data. Table 1 presents the tone partitions of MLPs used for $1 \times 1,2 \times 2,3 \times 3$ and $4 \times 4$ MIMO-OFDM systems as similar to IEEE $802.11 \mathrm{n}$ [10]. The examples of tone interleaving of MLPs across two transmitted antennas are illustrated in Figs. 2 and 3. In Fig. 2, MLPs are rearranged. $\left(\frac{M L P_{3}}{M L P_{54}}=-1, \frac{C L P_{3}}{C L P_{54}}=+1\right)$ is one of the odd pairs; $\left(\frac{M L P_{2}}{M L P_{55}}=-1, \frac{C L P_{2}}{C L P_{55}}=+1\right)$ is one of the even pairs. Odd pairs and even pairs all satisfy:

$$
\begin{aligned}
\frac{\operatorname{MLP}(f)}{\operatorname{MLP}(-f)} & =-1 \cdot \frac{\operatorname{CLP}(f)}{\operatorname{CLP}(-f)} \\
\Rightarrow & \frac{\operatorname{MLP}_{k}}{\operatorname{MLP}_{57-k}}=-1 \cdot \frac{\mathrm{CLP}_{k}}{\operatorname{CLP}_{57-k}}, k \in \mathbb{Z} \text { and } 1 \leq k \leq 56
\end{aligned}
$$

where $\mathrm{CLP}_{k}$ and $\mathrm{MLP}_{k}$ denote the $k^{\text {th }}$ fraction (data subcarrier) of CLP and MLP, respectively. Based on these pairs satisfying the property above, the proposed method can utilize these pairs to estimate the frequency-dependent $\mathrm{I} / \mathrm{Q}$ imbalance. In a $2 \times 2$ MIMO-OFDM system, due to frequency-selective fading, different antenna will receive different ratios of the received CLPs and the received MLPs. Therefore, the frequency-dependent I/Q imbalance can be estimated in each receiver. In order to make sure the accuracy of the estimation, there are at least $1 / 3$ fractions of MIMO long preambles distributing uniformly to satisfy Eq. (1).

\subsection{I/Q Imbalance Model}

Figure 4 displays the model of frequency-dependent I/Q imbalances [3]. The I/Q imbalance caused by the local oscillator (LO) can be characterized with an amplitude mismatch $\mathrm{g}=(1+\varepsilon)$ and a phase error $\theta$; ideally $\mathrm{g}=1$ and $\theta=0$. In this study, I/Q signals are filtered by two mismatched LPFs with frequency responses of $H_{I}(f)$ and $H_{g}(f)$, respectively; different received antennas contain different frequency-dependent $\mathrm{I} / \mathrm{Q}$ imbalances. In each received antenna, the LO signal of the mismatch quadrature demodulator is modeled as follows:

$$
\begin{aligned}
X_{L O}(t) & =I_{L O}(t)+j Q_{L O}(t) \\
& =\varphi_{1} z(t)+\varphi_{2} z^{*}(t)
\end{aligned}
$$

The coefficients $\varphi_{1}$ and $\varphi_{2}$ in Eq. (2) are

$\varphi_{1}=\left[1+g e^{-j \theta}\right] / 2$

$\varphi_{2}=\left[1-g e^{j \theta}\right] / 2$ 


\begin{tabular}{|c|c|c|c|c|c|c|c|c|}
\hline $\begin{array}{c}\text { Common Short Preambles } \\
\text { (CSP) }\end{array}$ & $\begin{array}{c}\text { Common Long Preamble } \\
\text { (CLP) }\end{array}$ & $\begin{array}{l}\text { Packet } \\
\text { Type }\end{array}$ & $\begin{array}{c}\text { MIMO Short Preambles } \\
\text { (MSP) }\end{array}$ & $\begin{array}{l}\text { MIMO Long Preamble } \\
\left(1^{\text {st }} \text { MLP }\right)\end{array}$ & $\bullet \bullet$ & $\begin{array}{l}\text { MIMO Long Preamble } \\
\left(\mathrm{N}^{\mathrm{th}} \mathrm{MLP}\right)\end{array}$ & Data Part 1 & Antenna 1 \\
\hline $\begin{array}{c}\text { Common Short Preambles } \\
\text { (CSP) }\end{array}$ & $\begin{array}{c}\text { Common Long Preamble } \\
\text { (CLP) }\end{array}$ & $\begin{array}{l}\text { Packet } \\
\text { Type }\end{array}$ & $\begin{array}{l}\text { MIMO Short Preambles } \\
\text { (MSP) }\end{array}$ & $\begin{array}{l}\text { MIMO Long Preamble } \\
\left(1^{\text {st } M L P)}\right.\end{array}$ & $\bullet \bullet$ & $\begin{array}{l}\text { MIMO Long Preamble } \\
\left(\mathrm{N}^{\mathrm{th}} \mathrm{MLP}\right)\end{array}$ & Data Part 2 & \multirow[t]{2}{*}{ Antenna 2} \\
\hline & & & & 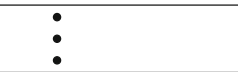 & & & & \\
\hline $\begin{array}{c}\text { Common Short Preambles } \\
\text { (CSP) }\end{array}$ & $\begin{array}{c}\text { Common Long Preamble } \\
\text { (CLP) }\end{array}$ & $\begin{array}{c}\text { Packet } \\
\text { Type }\end{array}$ & $\begin{array}{c}\text { MIMO Short Preambles } \\
\text { (MSP) }\end{array}$ & $\begin{array}{l}\text { MIMO Long Preamble } \\
\left(1^{\mathrm{st}} \mathrm{MLP}\right)\end{array}$ & $\bullet \bullet$ & $\begin{array}{l}\text { MIMO Long Preamble } \\
\left(\mathrm{N}^{\text {th }} \text { MLP) }\right.\end{array}$ & Data Part N & Antenn \\
\hline
\end{tabular}

Figure 1 The preamble format of the desired $\mathrm{N} \times \mathrm{N}$ MIMO-OFDM system.

proof

$\cos \left(2 \pi f_{c} t\right)-j g \sin \left(2 \pi f_{c} t+\theta\right)=\frac{1}{2}\left(e^{-j 2 \pi f_{c} t}+e^{j 2 \pi f_{c} t}\right)+\frac{1}{2} g\left(e^{-j\left(2 \pi f_{c} t+\theta\right)}-e^{j\left(2 \pi f_{c} t\right)}\right)$ $=\frac{1}{2}\left(1+g e^{-j \theta}\right) e^{-j 2 \pi f_{c} t}+\frac{1}{2}\left(1-g e^{j \theta}\right) e^{j 2 \pi f_{c} t}$

With Fourier transformation, the baseband signal of each received antenna is denoted as

$$
\begin{aligned}
R_{B B}(f) & =I_{B B}(f)+j Q_{B B}(f) \\
& =I_{L O}(f) H_{I}(f)+j Q_{L O}(f) H_{Q}(f) \\
& =\alpha(f) Z(f)+\beta(f) Z^{*}(-f)
\end{aligned}
$$

where

$\alpha(f)=\left[H_{I}(f)+H_{Q}(f) g e^{-j \theta}\right] / 2$

$\beta(f)=\left[H_{I}(f)-H_{Q}(f) g e^{j \theta}\right] / 2$

In Eq. (4), $Z^{*}(-f)$ is the image aliasing effect, caused by $\mathrm{I} / \mathrm{Q}$ distortions. It is also known that the baseband signal is distorted by self-mixing. The basic model [11, 12] is a special case of $H_{I}(f)=H_{Q}(f)$, where $\alpha(f)=$ $\left(1+g e^{-j \theta}\right) / 2$ and $\beta(f)=\left(1-g e^{j \theta}\right) / 2$. Figure 5 plots the channel frequency response (CFR) influenced by frequency-dependent I/Q imbalance with $1-\mathrm{dB}$ gain error, $10^{\circ}$-phase error \& $20^{\circ}$-phase error, and $180^{\circ}$-filter mismatch [3], in which FDI induces high-frequency distortions.

\subsection{Problem Statement}

For packet accesses, if one of data bits can not be decoded correctly, the entire packet will be discarded and resent. It means that $\mathrm{I} / \mathrm{Q}$ distortions must be calibrated before receiving data. Most studies [6-8] can provide a high IRR without a significant loss of SNR, but special data or more than 1000 frames are needed. Besides, filter mismatches are less addressed. Furthermore, CLPs and MLPs do not carry full I/Q information for all sub-carriers to balance throughput and performance. According to above issues, the objective of this study is to derive an efficient solution for frequencydependent I/Q imbalances as well-matched to IEEE 802.11n [10] and new specifications discussed in IEEE 802.11 VHT study group.

\section{Joint-estimation Algorithm}

To reduce the computation complexity, CFRs are estimated by the intersection of MLPs since all MLPs are toneinterleaved across different antennas, shown in Figs. 2 and 3 . In the case of $2 \times 2$ MIMO-OFDM systems, four estimated CFRs are $\hat{H}_{11}(f), \hat{H}_{12}(f), \hat{H}_{21}(f)$ and $\hat{H}_{22}(f)$ respectively, where $\hat{H}_{i j}(f)$ denotes the estimated CFR from the $i^{\text {th }}$ transmitted antenna to the $j^{\text {th }}$ received antenna. Since there are two cases of $\mathrm{MLP}_{k} / \mathrm{MLP}_{57-k}$ satisfying $\left(\mathrm{MLP}_{k} / \mathrm{MLP}_{57-k}\right) /\left(\mathrm{CLP}_{k} / \mathrm{CLP}_{57-k}\right)=-1, \hat{H}_{11}(f), \hat{H}_{12}(f)$, $\hat{H}_{21}(f)$ and $\hat{H}_{22}(f)$ are first estimated from the received
Table 1 Tone partitions

\begin{tabular}{|c|c|c|c|c|}
\hline Antenna number & Set 0 & Set 1 & Set 2 & Set 3 \\
\hline 0 & $\begin{array}{l}{[-28: 1:-1]} \\
{[1: 1: 28]}\end{array}$ & & & \\
\hline 1 & $\begin{array}{l}{[-28: 2:-2]} \\
{[2: 2: 28]}\end{array}$ & $\begin{array}{l}{[-27: 2:-1]} \\
{[1: 2: 27]}\end{array}$ & & \\
\hline 2 & $\begin{array}{l}{[-28: 3: 1]} \\
{[2: 3: 26]}\end{array}$ & $\begin{array}{l}{[-27: 3:-3]} \\
{[3: 3: 27]}\end{array}$ & $\begin{array}{l}{[-26: 3:-2]} \\
{[1: 3: 28]}\end{array}$ & \\
\hline 3 & $\begin{array}{l}{[-28: 4:-4]} \\
{[1: 4: 25]}\end{array}$ & $\begin{array}{l}{[-27: 4:-3]} \\
{[2: 4: 26]}\end{array}$ & $\begin{array}{l}{[-26: 4:-2]} \\
{[3: 4: 27]}\end{array}$ & $\begin{array}{l}{[-25: 4:-2]} \\
{[4: 4: 28]}\end{array}$ \\
\hline
\end{tabular}
of MLPs for $1 \times 1,2 \times 2,3 \times 3$ and $4 \times 4$ MIMO-OFDM systems. 
Tx 1

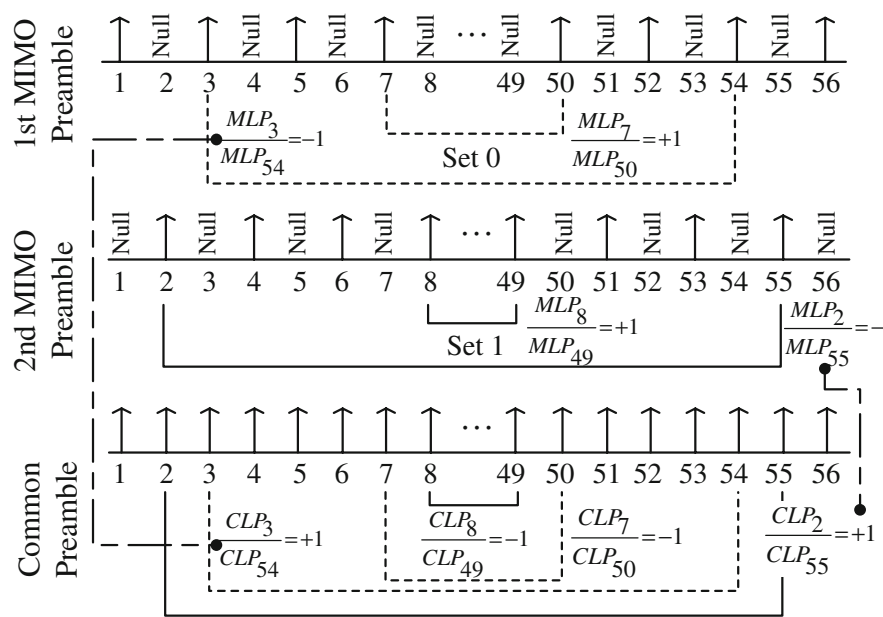

------ represents the odd pairs which satisfy $\frac{M L P_{k}}{M L P_{57-k}}=-1 \times \frac{C L P_{k}}{C L P_{57-k}}$
Tx 2

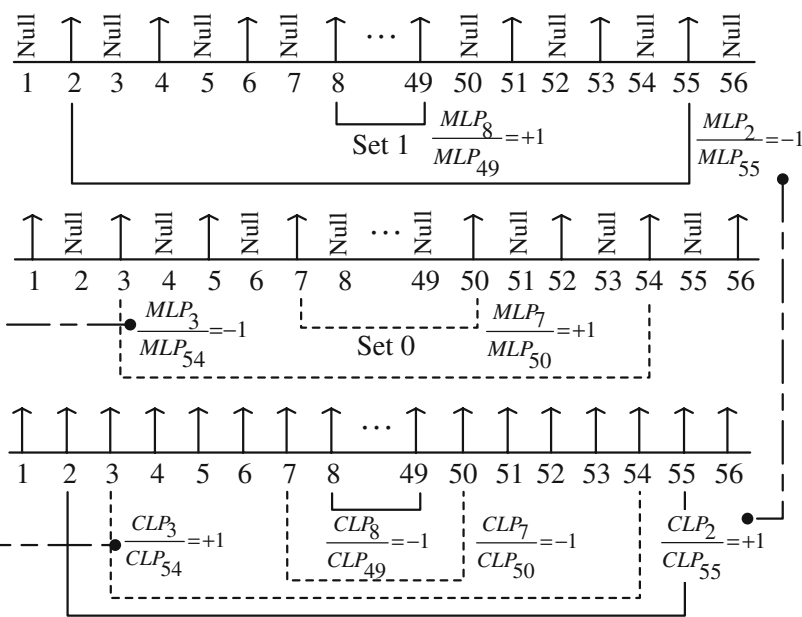

$\frac{M L P_{k}}{M L P_{57-k}}=-1 \times \frac{C L P_{k}}{C L P_{57-k}}$

$-\bullet$ represents a matching pair between CLPs and MLPs

Figure 2 Cross-validation characteristic in $2 \times 2$ MIMO-OFDM system.

MLPs with $\mathrm{MLP}_{k} / \mathrm{MLP}_{57-k}=+1$, as revealed in following equations.

$\hat{H}_{11}(f)=\alpha_{1}(f) H_{11}(f)+\beta_{1}(f) H_{11}^{*}(-f)$

$\hat{H}_{12}(f)=\alpha_{2}(f) H_{12}(f)+\beta_{2}(f) H_{12}^{*}(-f)$

$\hat{H}_{21}(f)=\alpha_{1}(f) H_{21}(f)+\beta_{1}(f) H_{21}^{*}(-f)$

$\hat{H}_{22}(f)=\alpha_{2}(f) H_{22}(f)+\beta_{2}(f) H_{22}^{*}(-f)$

where $\alpha_{1}(f), \alpha_{2}(f), \beta_{1}(f)$ and $\beta_{2}(f)$ indicate the frequencydependent $\mathrm{I} / \mathrm{Q}$ imbalances in the 1 st and 2 nd received antennas, and $H_{11}(f), H_{12}(f), H_{21}(f)$ and $H_{22}(f)$ are the ideal CFR of frequency-selective fading in each path. The received CLP in the 1st received antenna is

$$
\begin{aligned}
R_{1}(f) & =\alpha_{1}(f)\left\{H_{11}(f) \operatorname{CLP}(f)+H_{21}(f) \operatorname{CLP}(f)\right\} \\
& +\beta_{1}(f)\left\{H_{11}^{*}(-f) \operatorname{CLP}^{*}(-f)+H_{21}^{*}(-f) \operatorname{CLP}^{*}(-f)\right\}
\end{aligned}
$$

Due to the image aliasing effect of frequency-dependent $\mathrm{I} / \mathrm{Q}$ imbalance, the relation between $\mathrm{MLP}_{k} / \mathrm{MLP}_{57-k}$ and $\mathrm{CLP}_{k} / \mathrm{CLP}_{57-k}$ can be applied to extract the mismatches of filters, gains and phases. With $\mathrm{MLP}_{k} / \mathrm{MLP}_{57-k}=+1$ and

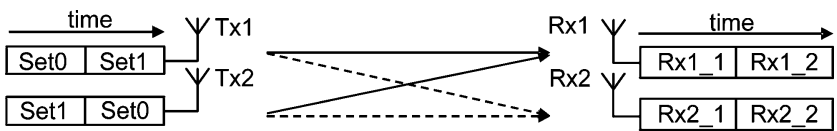

Figure 3 Tone interleaving of MLPs across two transmitted antennas.
$\mathrm{CLP}_{k} / \mathrm{CLP}_{57-k}=-1$, the mathematical derivations imply the following ratio of $\beta$ to $\alpha$ (see Appendix for the details).

$\frac{\beta_{1}(f)}{\alpha_{1}^{*}(-f)}=\frac{R_{1}(f)-\operatorname{CLP}(f) \hat{H}_{11}(f)-\operatorname{CLP}(f) \hat{H}_{21}(f)}{R_{1}^{*}(-f)-\operatorname{CLP}(f) \hat{H}_{11}^{*}(-f)-\operatorname{CLP}(f) \hat{H}_{21}^{*}(-f)}$

Denote the ratio $D_{1}(f)=\beta_{1}(f) / \alpha_{1}^{*}(-f)$. Since some fractions of MLPs are not $\left(\mathrm{MLP}_{k} / \mathrm{MLP}_{57-k}\right)=+1$, Eq. (8) is

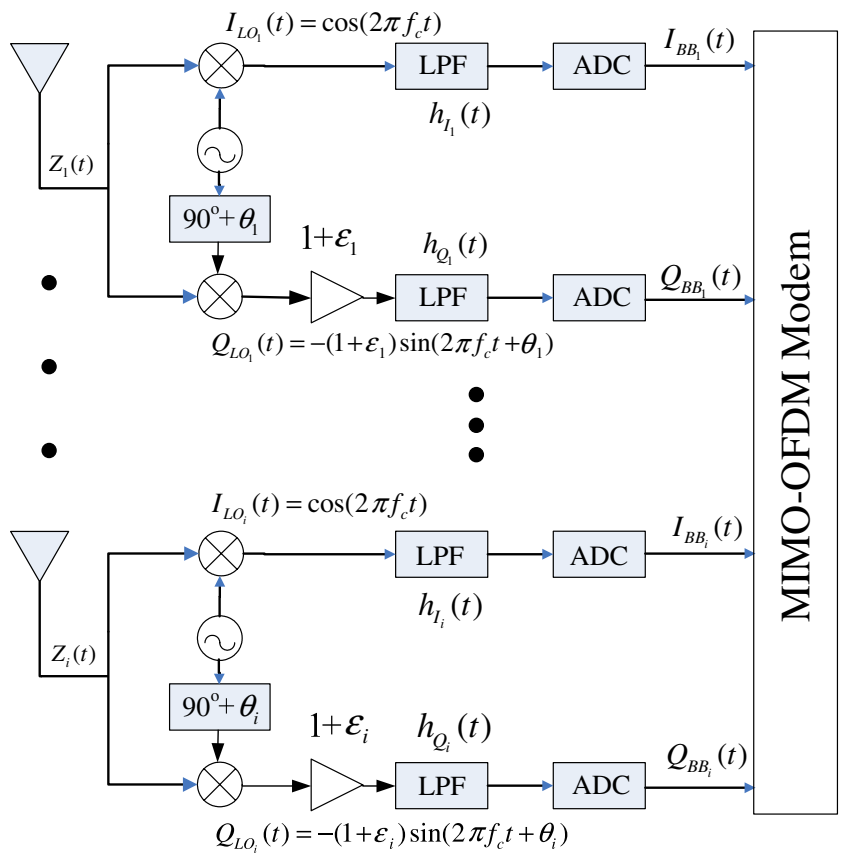

Figure 4 The model of frequency-dependent I/Q imbalances in MIMO-OFDM systems. 
Figure 5 Amplitude and phase of CFR with $h_{I}(t):\left[\begin{array}{ll}1 & 0.1\end{array}\right], h_{g}(t)$ : [0.1 1], (1-dB gain error, $10^{\circ}$ phase error) and (1-dB gain error, $20^{\circ}$ phase error): (a) amplitude; and (b) phase.
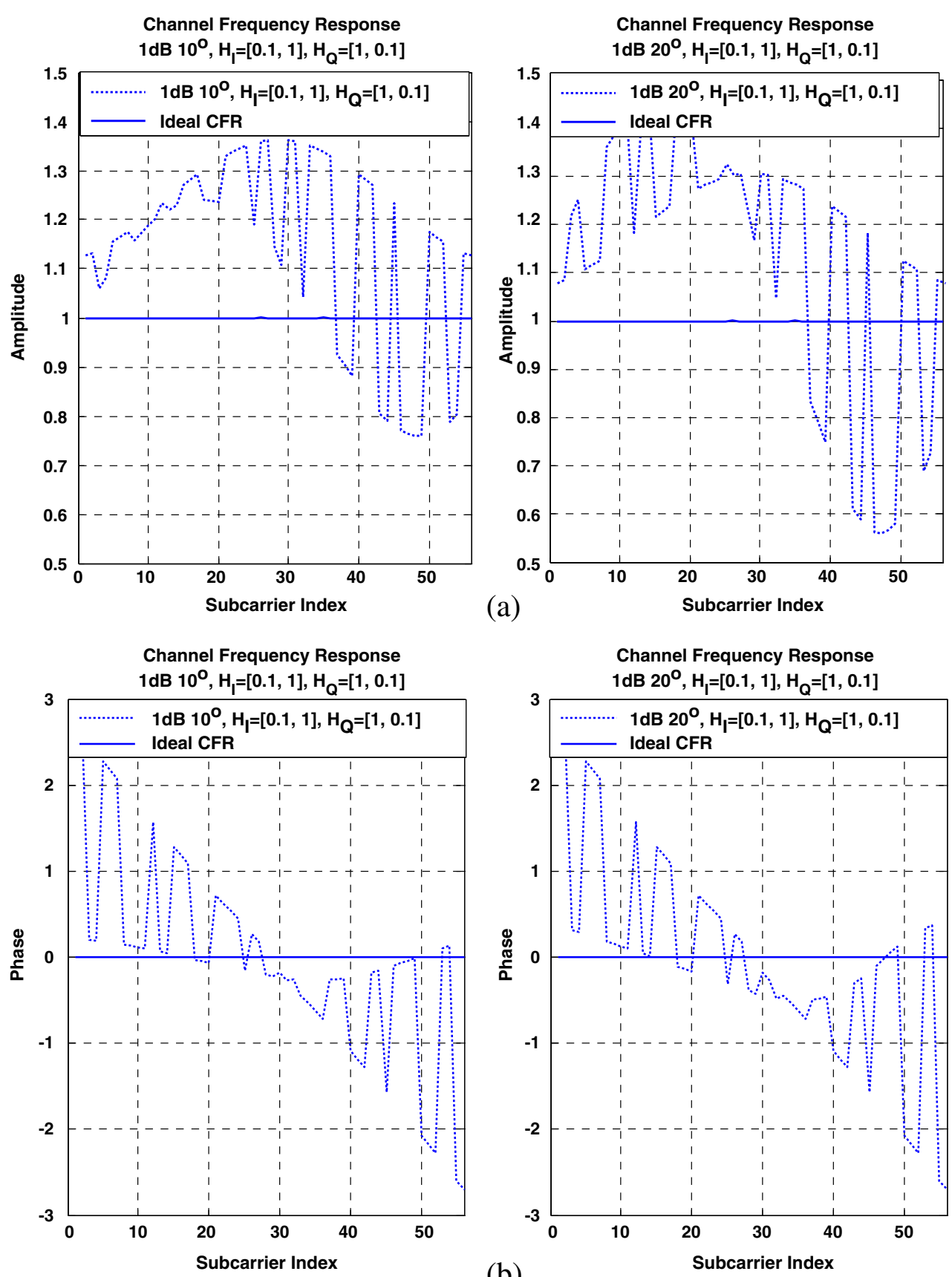

(b)

process are employed to measure the frequencydependent I/Q imbalance. Only one CLP and two MLPs are used in operations. For the case of an $\mathrm{N} \times \mathrm{N}$ MIMOOFDM system, the ratio $D_{1}(f)$ of the $j^{\text {th }}$ received antenna becomes

$$
\frac{\beta_{1}(f)}{\alpha_{1}^{*}(-f)}=\frac{R_{1}(f)-\operatorname{CLP}(f) \hat{H}_{11}(f)-\operatorname{CLP}(f) \hat{H}_{21}(f)}{R_{1}^{*}(-f)+\operatorname{CLP}(-f) \hat{H}_{11}^{*}(-f)+\operatorname{CLP}(-f) \hat{H}_{21}^{*}(-f)}
$$

Then the complete ratio $D_{1}(f)$ is to join Eqs. (8) and (9) together. In the 2 nd received antenna, the same

$$
\frac{\beta_{j}(f)}{\alpha_{j}^{*}(-f)}=\frac{R_{j}(f)-\sum_{k=1}^{N} \operatorname{CLP}(f) \hat{H}_{k j}(f)}{R_{j}^{*}(-f)-\sum_{k=1}^{N} \operatorname{CLP}(f) \hat{H}_{k j}^{*}(-f)}
$$




$$
\frac{\beta_{j}(f)}{\alpha_{j}^{*}(-f)}=\frac{R_{j}(f)-\sum_{k=1}^{N} \operatorname{CLP}(f) \hat{H}_{k j}(f)}{R_{j}^{*}(-f)+\sum_{k=1}^{N} \operatorname{CLP}(-f) \hat{H}_{k j}^{*}(-f)}
$$

The converged cycles are "N+1" (one CLP and N MLPs). Due to insufficient information in the CLP and MLPs, the complete $D_{1}(f)$ for all sub-carriers can not be accomplished by preambles directly. For example, only 24 sub-carriers of IEEE $802.11 \mathrm{n}$ enable to measure $D(f)$ in each received antenna; however, the ratios of the remainder sub-carriers can be discovered using interpolation.

After interpolation and smoothing, the compensation factor $Z_{1}(f)$ for the 1 st received antenna can be given by

$Z_{1}(f)=\frac{\alpha_{1}^{*}(-f) R_{1}(f)-\beta_{1}(f) R_{1}^{*}(-f)}{\alpha_{1}(f) \alpha_{1}^{*}(-f)-\beta_{1}(f) \beta_{1}^{*}(-f)}$

Assuming that $\alpha_{1}(-f)=1$ and $\beta_{1}(f)=D_{1}(f)$, Eq. (11) becomes

$Z_{1}(f)=\frac{R_{1}(f)-D_{1}(f) R_{1}^{*}(-f)}{1-D_{1}(f) D_{1}^{*}(-f)}$

Based on Eq. (12), a FD filter with the coefficients of $D_{1}(f)$ is acquired to compensate for frequency-dependent $\mathrm{I} /$ $\mathrm{Q}$ imbalance in the $1 \mathrm{st}$ received antenna. For the $j^{\text {th }}$ received antenna, the same method can be applied to obtain the complete $D_{j}(f)=\frac{\beta_{j}(f)}{\alpha_{*}^{*}(-f)}$ and $Z_{j}(f)$. According to Eqs. (8), (9) and (12), Fig. 6 is the architecture of the crossvalidation estimator, and Fig. 7 is the architecture of the FD-filter compensator. In Figs. 6 and 7, total 56 subcarriers (without nulls) must share all dividers, multipliers and adders of $D_{j}(f)$ and $Z_{j}(f)$ to balance clock rate, hardware cost and designed complexity. The function of $-f$ is easily implemented by the inversed buffer access with $[57-k]$ for the $k^{\text {th }}$ data sub-carrier. According to $\mathrm{MLP}_{k} / \mathrm{MLP}_{57-k}$ and $\mathrm{CLP}_{k} / \mathrm{CLP}_{57-k}$, two kinds of buffers, namely first-input first-output (FIFO) and first-input last-output (Stack), are adopted to measure $D_{j}(f)$ using one complex divider as displayed in Fig. 7. As interpolation is not essential for each sub-carrier, only one interpolator is needed in designs. The output of the cross-validation estimator must be serial to match the shared structure of the FD-filter compensator. All modules can be realized by hardware-description language (HDL) and synthesized for an in-house CMOS library by Design Analyzer (Synopsys).

\section{Simulation and Discussion}

A typical model [13] of frequency-selective fading was utilized to evaluate the proposed approach. The worst case of frequency-dependent I/Q is $2-\mathrm{dB}$ gain error, $20^{\circ}$ phase error and $180^{\circ}$-filter mismatch. This severe condition is applied to evaluate the proposed method for its robustness and effectiveness. The packet-error rate (PER) is the performance index and the required PER is $10 \%$ in the following conditions.

(1) $2 \times 2$ MIMO OFDM with a bandwidth of $20 \mathrm{MHhz}$.

(2) Data length of 1024 bytes.

(3) MCS 13: 64-QAM modulation and 2/3-coding rate.

(4) FEC: 6-bit Soft Viterbi decoder.

(5) Alamouti STBC.

(6) Frequency-selective fading: TGnD (rms:50 ns, 8 taps), and TGnE (rms:100 ns, 15 taps)

Three settings of frequency-dependent I/Q imbalances are:

a) Typical I/Q:

$1-\mathrm{dB}$ gain error, $10^{\circ}$ phase error in the $1 \mathrm{st}$ antenna; $0.7-\mathrm{dB}$ gain error, $8^{\circ}$ phase error in the $2 \mathrm{nd}$ antenna.

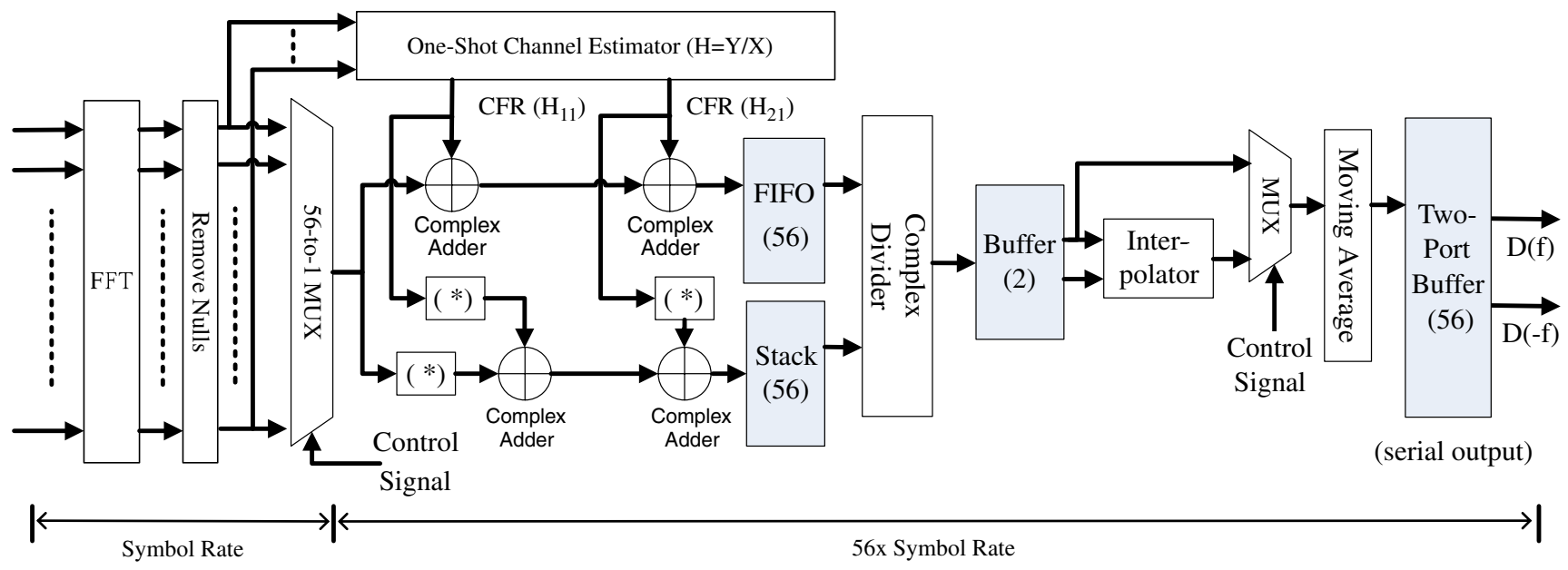

Figure 6 Architecture of the cross-validation estimator in each received antenna. 


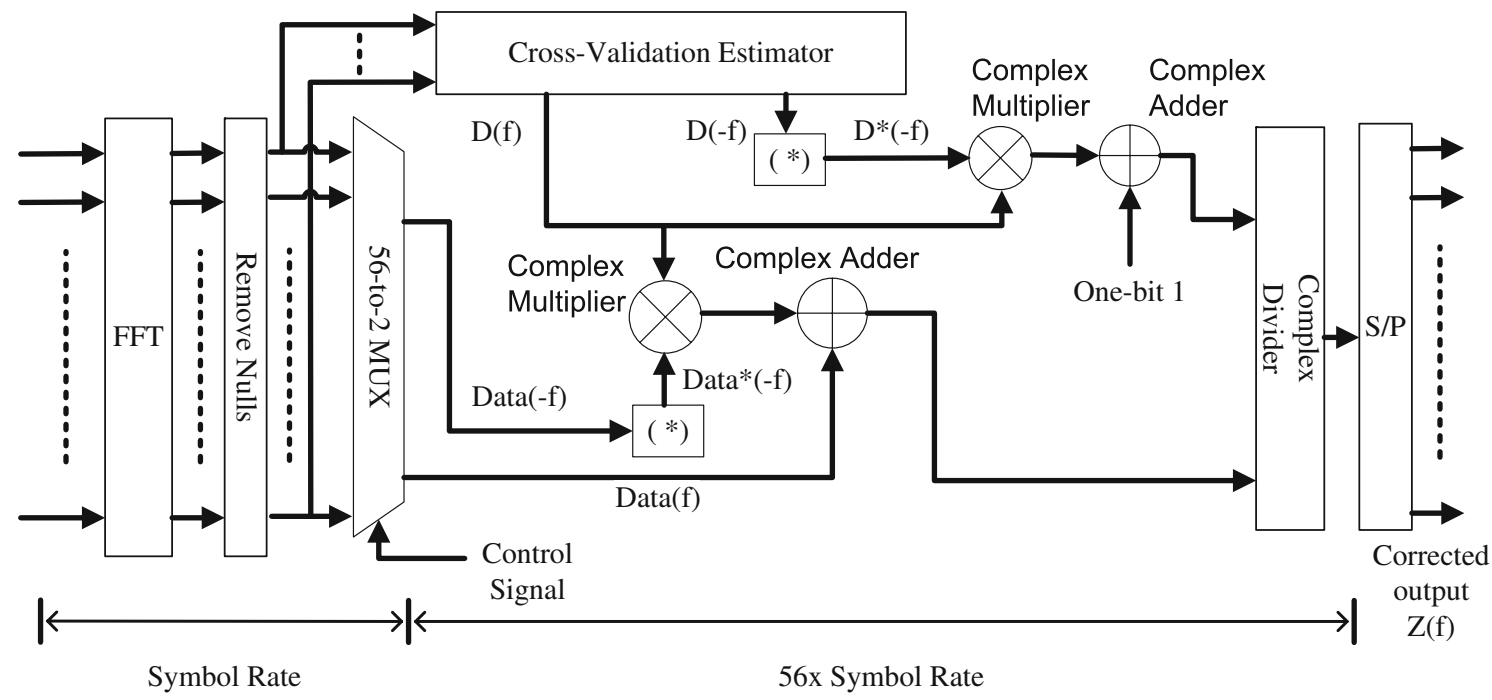

Figure 7 Architecture of the FD-filter compensator in each received antenna.

b) High $\mathrm{I} / \mathrm{Q}$ :

$1-\mathrm{dB}$ gain error, $20^{\circ}$ phase error in the $1 \mathrm{st}$ antenna; $2-\mathrm{dB}$ gain error, $10^{\circ}$ phase error in the $2 \mathrm{nd}$ antenna.

c) The worst FDI: $180^{\circ}$-filter mismatch [3]

i): The LPF of I: $h_{I}(t)=\left[\begin{array}{ll}1 & 0.1\end{array}\right]$ (time domain)

ii): The LPF of Q: $h_{Q}(t)=\left[\begin{array}{ll}0.1 & 1\end{array}\right]$ (time domain)

After compensations, the amplitude and phase of $\hat{H}_{11}(f)$ with 1 -dB gain error, $20^{\circ}$-phase error and $180^{\circ}$-filter mismatch of $h_{I}(t)=\left[\begin{array}{ll}1 & 0.1\end{array}\right]$ and $h_{Q}(t)=\left[\begin{array}{ll}0.1 & 1\end{array}\right]$ in TGnE (15 taps and 100-ns RMS delay spread) are shown in Fig. 8. It reveals that the high-frequency distortion of
FDI can be eliminated to make the CFR be close to that of frequency-selective fading. Even though there is a shift error, this solution performs well enough to make Alamouti equalization work. In Figs. 9 and 10, the conditions of frequency-selective fading are $\mathrm{TGnD}(8$ taps and 50 -ns RMS delay spread) and TGnE (15 taps and 100-ns RMS delay spread); I/Q imbalances are typical I/Q and high I/Q; and FDI is the worst $180^{\circ}$-filter mismatch. When channel estimation is not perfect, the system degradation is within 2.9-3.1 dB under typical I/Q with the worst FDI. With ideal channel estimations, the SNR losses of the proposed algorithm are within $1 \mathrm{~dB}$ and $1.2 \mathrm{~dB}$. In order to be compatible with IEEE $802.11 \mathrm{n}$, only 3 preambles are available to estimate FDI I/Q imbalance via the proposed

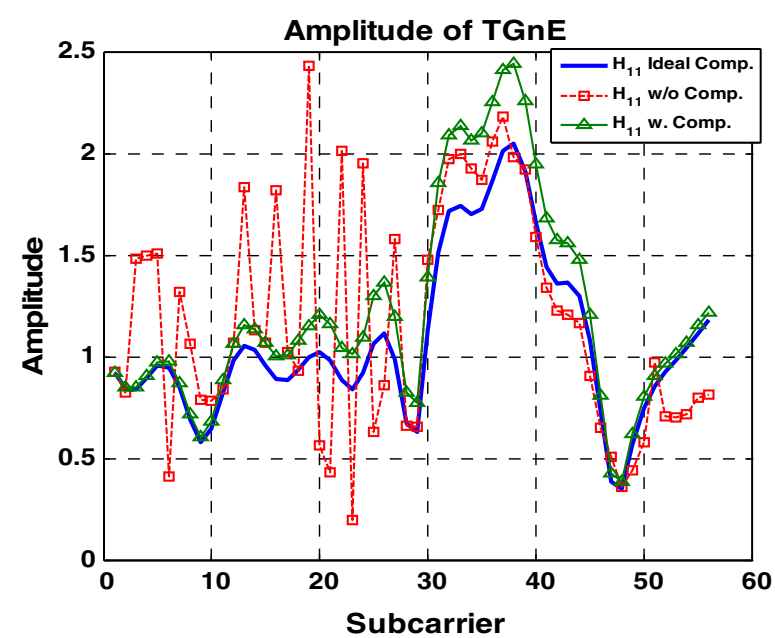

(a)

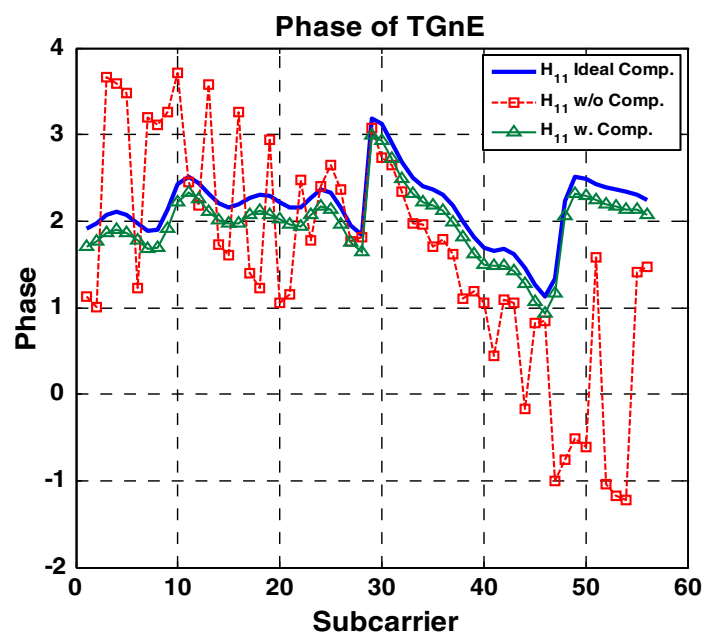

(b)

Figure 8 Amplitude and phase of CFR $h_{11}$ with $h_{I}(t):[1,0.1], h_{g}(t):[0.1,1], 1-\mathrm{dB}$ gain error and $20^{\circ}$-phase error in TGnE: (a) amplitude; and (b) phase. 


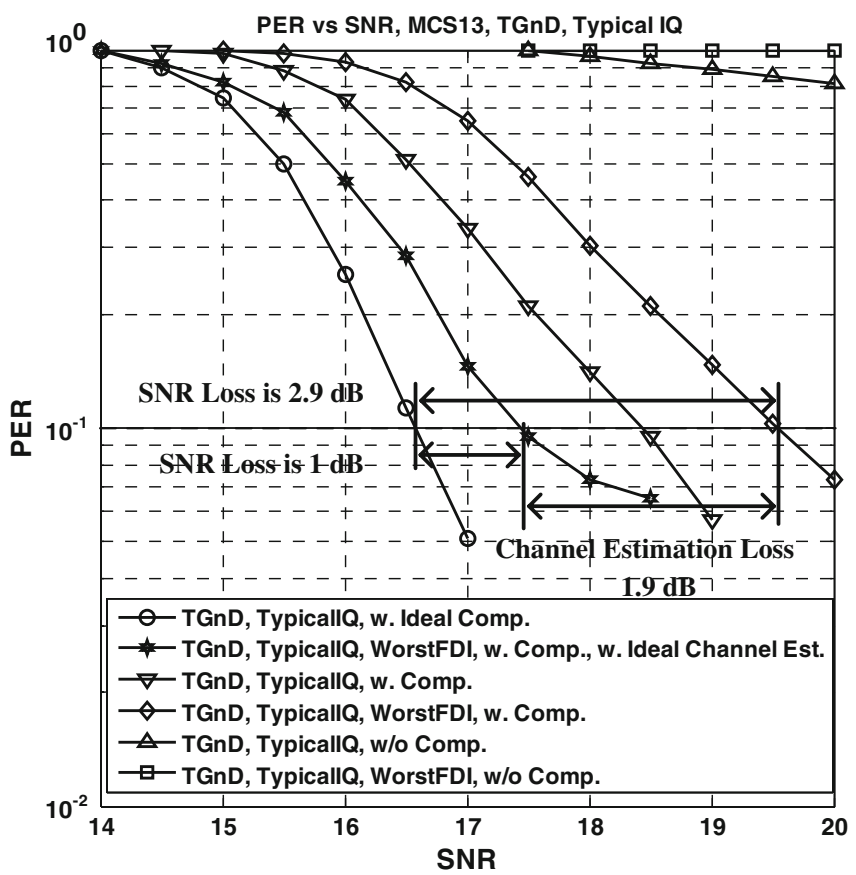

(a)

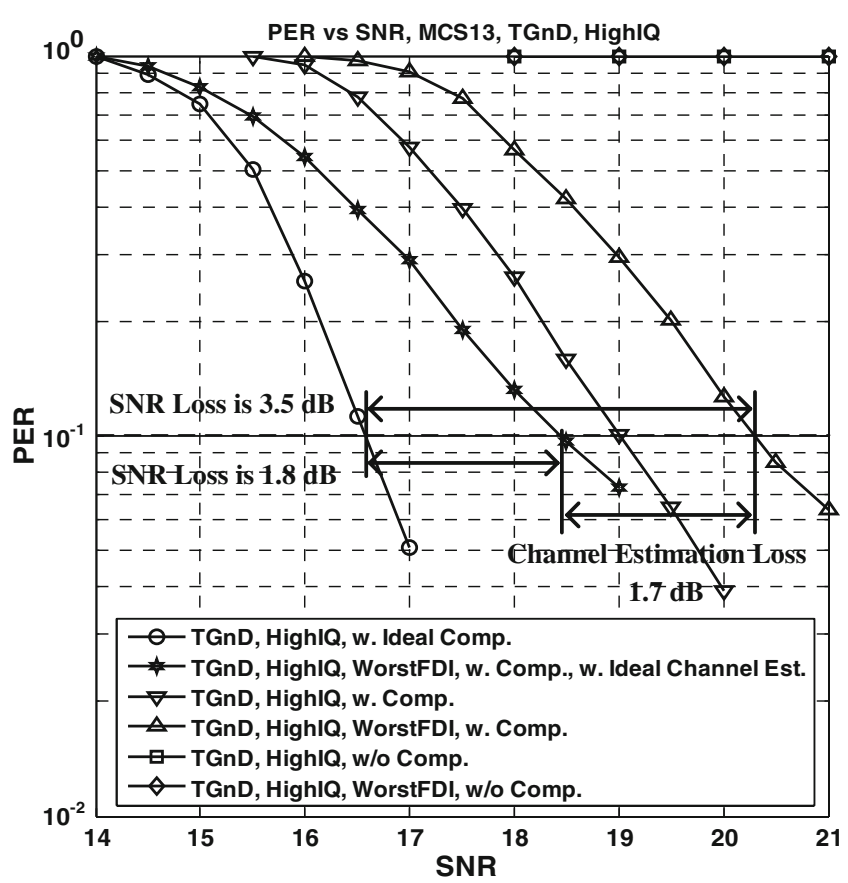

(b)

Figure 9 PER versus SNR, MCS 13 and TGnD with/without FDI: (a) Typical I/Q and (b) High I/Q.

method. It results in an additional 1.2-dB SNR loss. It is also known that the SNR losses are more sensitive to frequency-dependent $\mathrm{I} / \mathrm{Q}$ imbalances than frequencyselective fading. Since 50-dB IRR is not excellent, OFDM pilots with the adaptive scheme [7] as a fine estimation can be exploited to enhance performance.

Since only 3 preambles with interleaving property are valid to estimate the frequency-dependent I/Q imbalance,

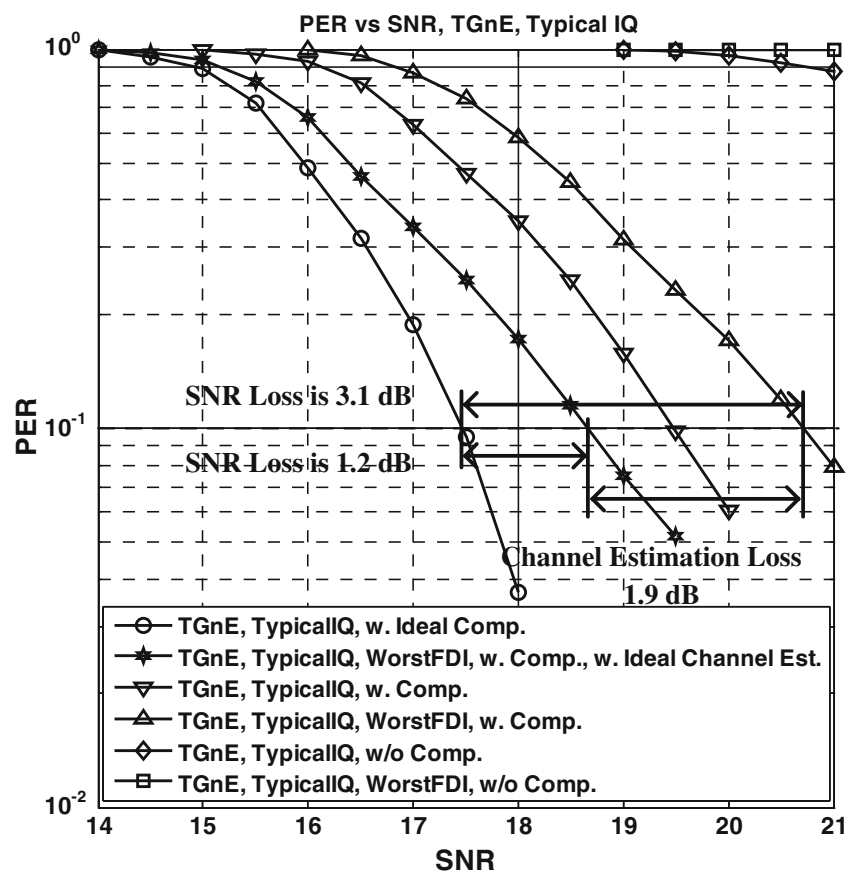

(a)

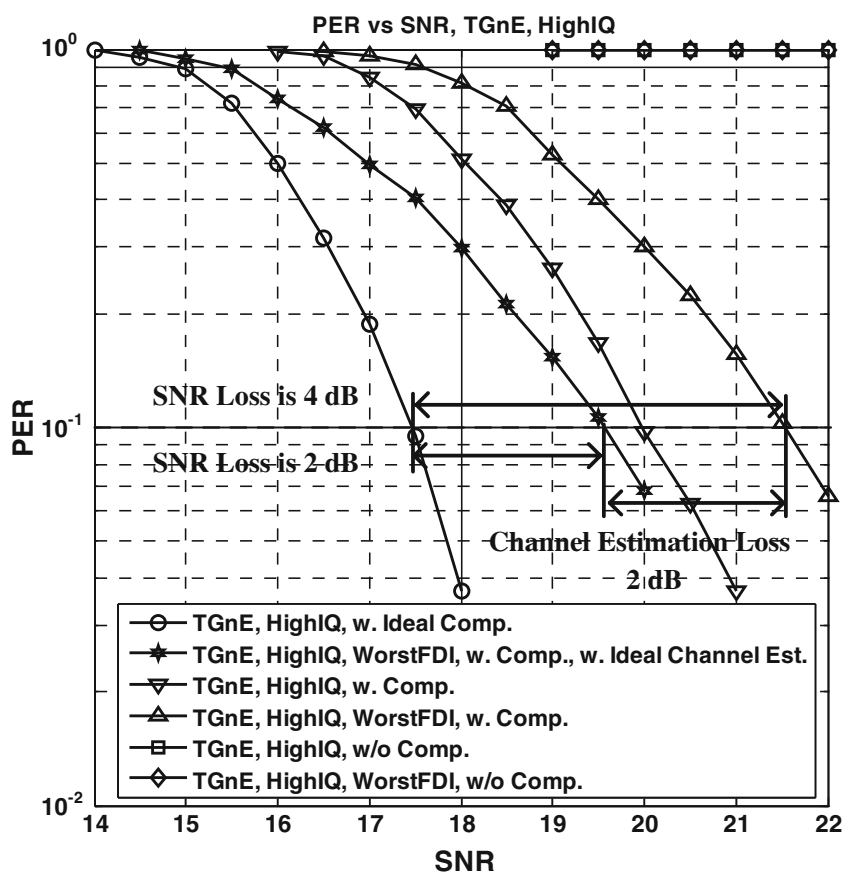

(b)

Figure 10 PER versus SNR, MCS 13 and TGnE with/without FDI: (a) Typical I/Q ; and (b) High I/Q. 
Table 2 Summary of the designed features.

\begin{tabular}{|c|c|c|c|c|c|c|c|}
\hline & $\operatorname{Ref}[3]$ & $\operatorname{Ref}[4]$ & $\operatorname{Ref}[5]$ & $\operatorname{Ref}[6]$ & $\operatorname{Ref}[7]$ & $\operatorname{Ref}[8]$ & Proposed work \\
\hline System type & $\begin{array}{c}\text { OFDM+ } \\
\text { QPSK }\end{array}$ & OFDM & $\begin{array}{l}\text { MIMO } \\
\text { OFDM }\end{array}$ & $\begin{array}{l}\text { MIMO OFDM+64 } \\
\text { QAM }\end{array}$ & $\begin{array}{l}\text { Single Carrier+16 } \\
\text { QAM }\end{array}$ & $\begin{array}{l}\text { OFDM+64 } \\
\text { QAM }\end{array}$ & $\begin{array}{l}\text { MIMO OFDM+64 } \\
\text { QAM }\end{array}$ \\
\hline Method & $\begin{array}{l}\text { NLS } \\
\text { estimation } \\
\& \text { FIR filter }\end{array}$ & $\begin{array}{l}\text { LS } \\
\text { estimation }\end{array}$ & $\begin{array}{l}\text { MMSE } \\
\text { estimation } \\
\text { \& RLS } \\
\text { filter }\end{array}$ & LS estimation & $\begin{array}{l}\text { LMS based } \\
\text { adaptive FIR } \\
\text { filter }\end{array}$ & $\begin{array}{l}\text { Blind } \\
\text { estimation }\end{array}$ & $\begin{array}{l}\text { Cross-validation } \\
\text { estimation \& FD } \\
\text { filter }\end{array}$ \\
\hline $\begin{array}{l}\text { Required } \\
\text { format }\end{array}$ & $\begin{array}{l}\text { Special Pilot } \\
\text { Symbol }\end{array}$ & $\begin{array}{l}\text { Special } \\
\text { pilot }\end{array}$ & $\begin{array}{l}\text { Long } \\
\text { preamble }\end{array}$ & $\begin{array}{l}\text { Alamouti-coded } \\
\text { data }\end{array}$ & Data & Data & Long preamble \\
\hline $\begin{array}{l}\mathrm{I} / \mathrm{Q} \\
\text { Estimation }\end{array}$ & One-shot & One-shot & Adaptive & One-shot & Adaptive & Adaptive & One-shot \\
\hline $\begin{array}{l}\text { Converged } \\
\text { cycles }\end{array}$ & 10 & 10 & $30-35$ & $2(2 \times 1$ MIMO $)$ & 4000 Frames & 1000 & $\begin{array}{l}3(2 \times 2 \text { MIMO }) \\
\mathrm{N}+1(\mathrm{~N} \times \mathrm{N} \text { MIMO })\end{array}$ \\
\hline $\begin{array}{l}\text { \# of } \\
\text { Multiplication }\end{array}$ & $>1600$ & 616 & 5376 & 594 & 8000 & 19000 & 206 \\
\hline \# of Addition & $>1500$ & 448 & 1312 & 216 & 8000 & 6000 & 358 \\
\hline $\begin{array}{l}\text { Filter } \\
\text { mismatch }\end{array}$ & Yes & No & No & No & No & No & Yes \\
\hline Compatibility & No & No & Yes & Yes & Yes & Yes & Yes \\
\hline Tolerant range & $1 \mathrm{~dB}, 5^{\circ}$ & $2 \mathrm{~dB}, 8^{\circ}$ & $0.45 \mathrm{~dB}, 2.81^{\circ}$ & $2 \mathrm{~dB}, 5^{\circ}$ & $3 \mathrm{~dB}, 30^{\circ}$ & $1.05 \mathrm{~dB}, 5^{\circ}$ & $\begin{array}{l}\mathrm{RX}_{1}: 1 \mathrm{~dB}, 10^{\circ} \\
\mathrm{RX}_{2}: 0.7 \mathrm{~dB}, 8^{\circ}\end{array}$ \\
\hline Fading channel & $\begin{array}{l}\text { Exponential } \\
\text { decay } \\
(3 \text { taps })\end{array}$ & $\begin{array}{l}\text { Frequency } \\
\text { selective } \\
(4 \text { taps })\end{array}$ & N/A & $\begin{array}{l}\text { Frequency } \\
\text { selective } \\
(4 \text { taps })\end{array}$ & Rayleigh & ETSI-A & $\begin{array}{l}\text { IEEE TGnE } \\
\text { (rms:100 ns, } 15 \text { taps) }\end{array}$ \\
\hline SNR loss & $<1 \mathrm{~dB}$ & About $1 \mathrm{~dB}$ & $3 \mathrm{~dB}$ & $<1 \mathrm{~dB}$ & N/A & $1-2 \mathrm{~dB}$ & $1.2 \mathrm{~dB}$ \\
\hline
\end{tabular}

fewer converged cycles are needed than other methods. The designed features are summarized in Table 2. Considering computational effort, 5 multiplications and 4 additions are required for acquiring one ratio of $\beta$ to $\alpha$ in Eq. (8). Since there are 24 ratios of $\beta$ to $\alpha$ needed to calculate, it costs 120 multiplications and 96 additions. Furthermore, taking interpolation and moving average into account, the total multiplications and additions are 206 and 358 respectively, which is more efficient than other references. Two major contributions of the proposed cross-validation scheme are summarized as following: 1) Backward compatible with IEEE 802.11n; 2) Low-computational complexity.
For algorithm verifications, a $2 \times 2$ software-defined radio (SDR) was constructed, as displayed in Fig. 11. The field programmable gate array (FPGA) chips (Xilinx Virtex-II) with on-board 14-bit digital-to-analog (D/A) and analog-todigital (A/D) converters are the interface between in-house RF modules and software. The packets are first generated by MATLAB and then transmitted to RF front-ends through 14bit D/As. In order to make MIMO transmissions coherent, there is an additional D/A module, as a hardware trigger, to control all D/As coherently at TX. After down-converting the RF signals into baseband at the receiver, analog signals are fed into four 14-bit A/Ds for quantization. The proposed
Figure 11 SDR platform for a $2 \times 2$ MIMO-OFDM system.

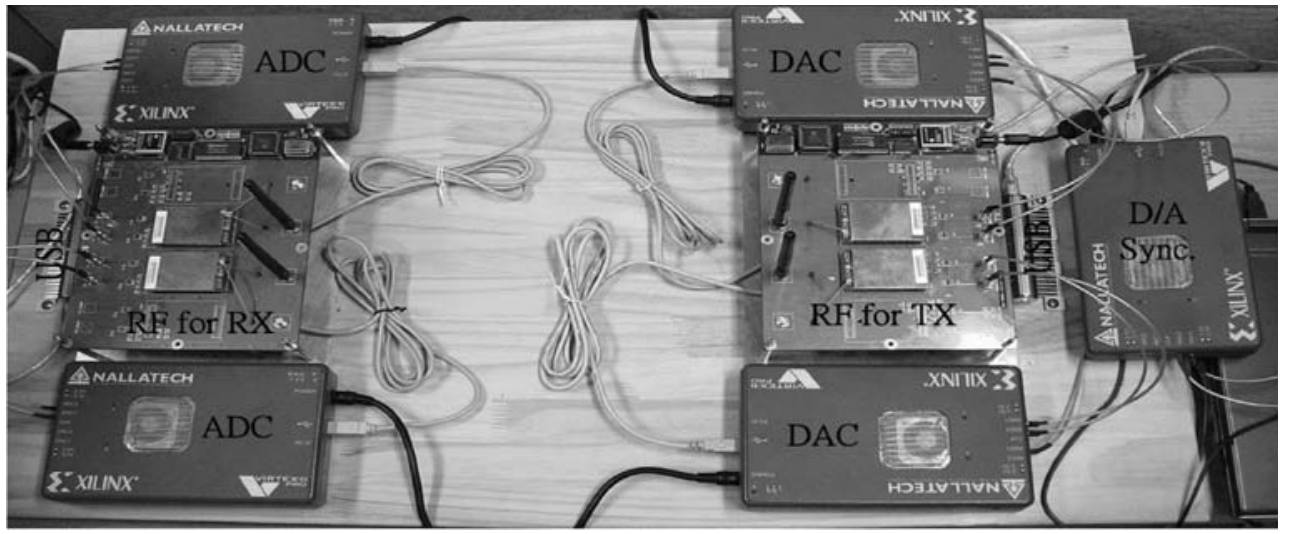




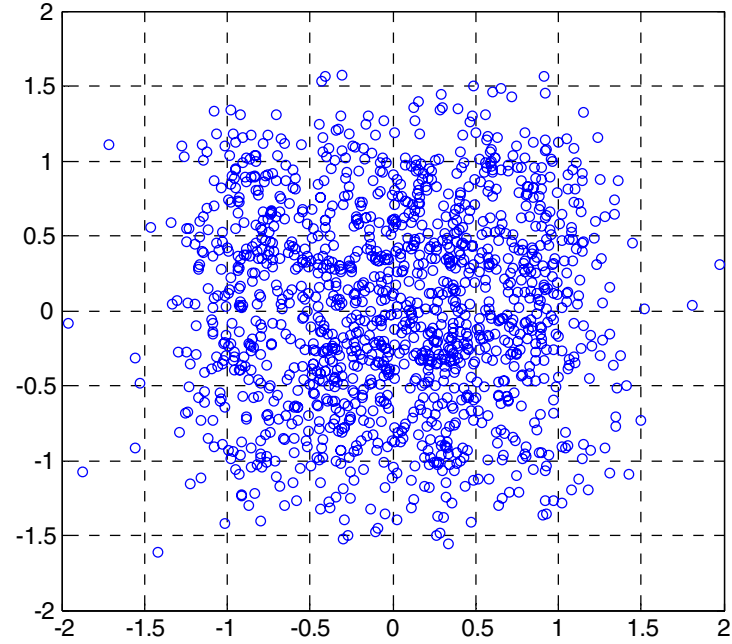

(a)

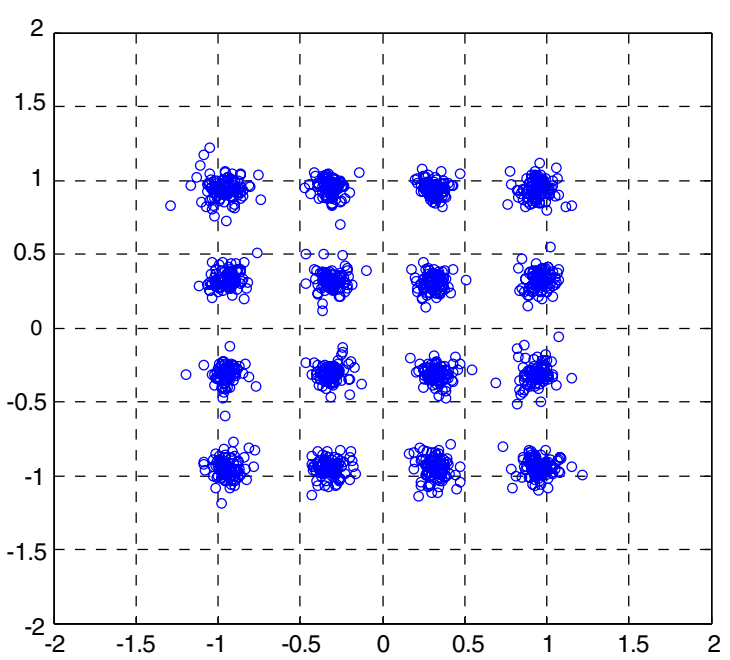

(b)

Figure 12 Measured 16-QAM constellations in the 1st received antenna: (a) before compensation ; and (b) after compensation.

algorithm then processes the quantized signals by using software (MATLAB). The measured 16-QAM constellations in the 1st received antenna are plotted in Fig. 12, where carrier synchronization [2] and equalization [14] have been included in the platform. The measured EVM without compensation and with compensation are $-1.9 \mathrm{~dB}$ and $21.35 \mathrm{~dB}$, respectively, which indicate that the proposed scheme can also work well for practice. Both simulations and measurements hint that this study ensures a MIMOOFDM receiver overcoming the problems of frequencydependent I/Q imbalances.

\section{Conclusion}

This work presents a low-computational estimation, using interleaving arrangement of preambles, to extract the mismatches of filters, gains and phases for MIMO-OFDM wireless accesses. Simulations and measurements indicate that the proposed scheme can solve frequency-dependent I/Q imbalances with 2 - $\mathrm{dB}$ gain errors, $20^{\circ}$-phase errors and the worst $180^{\circ}$-filter mismatches to achieve $10 \%$ PER in frequencyselective fading. With the help of cross validation, for $\mathrm{N} \times \mathrm{N}$ MIMO-OFDM systems, just $\mathrm{N}+1$ preambles are used in actions. This study does not only derive an efficient solution for frequency-dependent I/Q imbalances in OFDM-MIMO receivers, but also is well-suited to next-generation wireless LAN discussed in IEEE 802.11 VHT study group. Consequently, the system performance can be improved via the proposed method, which can loose the specification of RF design.

Acknowledgements This work was conducted under "A plan to actively participate in international standard organizations for wireless communications" of the Institute for Information Industry, MOEA, and supported by the National Science Council of Taiwan, ROC under Grant and NSC-97-2220-E-009-016.

\section{Appendix}

Derivation of Equation (8)

According to $\mathrm{CLP}^{*}(f)=\operatorname{CLP}(f)$, Eqs. (6a-6d) and (7), the baseband signal in the 1 st received antenna is

$$
\begin{aligned}
R_{1}(f) & =\alpha_{1}(f) H_{11}(f) \operatorname{CLP}(f)+\beta_{1}(f) H_{11}^{*}(-f) \operatorname{CLP}(-f) \\
& +\alpha_{1}(f) H_{21}(f) \operatorname{CLP}(f)+\beta_{1}(f) H_{21}^{*}(-f) \operatorname{CLP}(-f)
\end{aligned}
$$

Since $\left(\mathrm{CLP}_{k} / \mathrm{CLP}_{57-k}\right)=-1$ or $\operatorname{CLP}(f) / \operatorname{CLP}(-f)=-1$, Eq. (A.1) can be rewritten as

$$
\begin{aligned}
R_{1}(f) & =\alpha_{1}(f) H_{11}(f) \operatorname{CLP}(f)+\beta_{1}(f) H_{11}^{*}(-f)[\operatorname{CLP}(f)-2 \operatorname{CLP}(f)] \\
& +\alpha_{1}(f) H_{21}(f) \operatorname{CLP}(f)+\beta_{1}(f) H_{21}^{*}(-f)[\operatorname{CLP}(f)-2 \operatorname{CLP}(f)]
\end{aligned}
$$

Substituting Eqs. (6a) and (6c) into Eq. (A.2), it yields

$$
\begin{aligned}
R_{1}(f) & =\operatorname{CLP}(f) \hat{H}_{11}(f)+\operatorname{CLP}(f) \hat{H}_{21}(f) \\
& -2 \beta_{1}(f) \operatorname{CLP}(f)\left[H_{11}^{*}(-f)+H_{21}^{*}(-f)\right]
\end{aligned}
$$

With $\mathrm{CLP}_{k} / \mathrm{CLP}_{57-k}=-1$ or $\operatorname{CLP}(f) / \operatorname{CLP}(-f)=-1$, Eq. (A.1) can be also expressed as

$$
\begin{aligned}
R_{1}(f) & =\alpha_{1}(f) H_{11}(f)[\operatorname{CLP}(-f)-2 \operatorname{CLP}(-f)]+\beta_{1}(f) H_{11}^{*}(-f) \operatorname{CLP}(-f) \\
& +\alpha_{1}(f) H_{21}(f)[\operatorname{CLP}(-f)-2 \operatorname{CLP}(-f)]+\beta_{1}(f) H_{21}^{*}(-f) \operatorname{CLP}(-f)
\end{aligned}
$$

Substituting Eqs. (6a) and (6c) into Eq. (A.4), it yields

$$
\begin{aligned}
R_{1}(f) & =\operatorname{CLP}(-f) \hat{H}_{11}(f)+\operatorname{CLP}(-f) \hat{H}_{21}(f) \\
& -2 \alpha_{1}(f) \operatorname{CLP}(-f)\left[H_{11}(f)+H_{21}(f)\right]
\end{aligned}
$$


After replacing $f$ with $-f$, and making conjugate, Eq. (A.5) becomes

$$
\begin{aligned}
R_{1}^{*}(-f) & =\mathrm{CLP}^{*}(f) \hat{H}_{11}^{*}(-f)+\mathrm{CLP}^{*}(f) \hat{H}_{21}^{*}(-f) \\
& -2 \alpha_{1}^{*}(-f) \operatorname{CLP}^{*}(f)\left[H_{11}^{*}(-f)+H_{21}^{*}(-f)\right]
\end{aligned}
$$

According to $\operatorname{CLP}^{*}(f)=\operatorname{CLP}(f)$, the ratio of $\beta$ to $\alpha$ can be derived by Eqs. (A.3) and (A.6).

$$
\frac{\beta_{1}(f)}{\alpha_{1}^{*}(-f)}=\frac{R_{1}(f)-\operatorname{CLP}(f) \hat{H}_{11}(f)-\operatorname{CLP}(f) \hat{H}_{21}(f)}{R_{1}^{*}(-f)-\operatorname{CLP}(f) \hat{H}_{11}^{*}(-f)-\operatorname{CLP}(f) \hat{H}_{21}^{*}(-f)}
$$

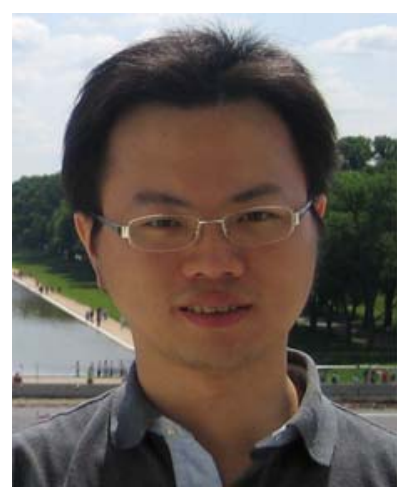

\section{References}

1. Nee, R. V., \& Parsed, R. (2000). OFDM for Wireless Multimedia Communication. MA: Artech House.

2. Heiskala, J., \& Terry, J. (2001). OFDM Wireless LANs: A Theoretical and Practical Guide. Indianapolis, Indiana: Sams.

3. Guanbin, X., Manyuan, S., \& Hui, L. (2005). Frequency offset and I/Q imbalance compensation for OFDM direct-conversion receivers. IEEE Trans. on Wireless Communications, 4(2), 673680.

4. Tarighat, A., \& Sayed, A. H. (2004). On the baseband compensation of IQ imbalances in OFDM systems. IEEE International Acoustics, Speech, and Signal Processing (ICASSP '04) Conference, 4, 1021-1024.

5. Rao, R. M., \& Daneshrad, B. (2007). I/Q mismatch cancellation for MIMO-OFDM systems. 15th IEEE International Symposium Personal, Indoor and Mobile Radio Communications (PIMRC), 4, 2710-2714.

6. Tarighat, A., \& Sayed, A. H. (2005). MIMO OFDM Receivers for Systems with IQ Imbalances. IEEE Transactions on Signal Processing, 53(9), 3583-3596.

7. Cetin, E., Kale, I., \& Morling, R. C. S. (2004). Adaptive selfcalibrating image rejection receiver. IEEE International Conference on Communications, 5, 2731-2735.

8. Windisch, M., \& Fettweis G. (2005). Standard-Independent I/Q Imbalance Compensation in OFDM Direct-Conversion Receivers, 13th European Signal Processing Conference (EUSIPCO'05)

9. Horlin, F., De Rore, S., Lopez-Estraviz, E., Naessens, F., \& Van der Perre, L. (2006). Impact of frequency offsets and IQ imbalance on MC-CDMA reception based on channel tracking. IEEE Journal on Selected Areas in Communications, 24(6), 11791188.

10. Wireless LAN Medium Access Control (MAC) and Physical Layer (PHY) Specifications, IEEE Std 802.11n, 2005.

11. Valkama, M., \& Renfors M. (2000). Advanced DSP for I/Q imbalance compensation in a low-IF receiver, in Proc. IEEE Int. Conf. on Communications, New Orleans, pp.768-772.

12. Valkama M., Renfors, M., \& Koivunen V. (2000). Blind source separation based I/Q imbalance compensation, in Proc. IEEE Symposium on Adaptive Systems for Signal Processing, Communications and Control, pp.310-314

13. IEEE P802.11 Wireless LANs, TGn Channel Models, May 2004.

14. Chiueh T. D., \& Tsai, P. Y. (2007). OFDM Baseband Receiver Design for Wireless Communications, John Wiley \& Sons.

Wei-Chi Lai received the B.S. degree from the Department of Computer Science Information Engineering, National Cheng-Kung University, Tainan, Taiwan, in 2004, and the M.S. degree from the Institute of Computer Science, National Chiao-Tung University, Hsinchu, Taiwan, in 2006. He is currently pursuing the Ph.D. degree in computer science from the National Chiao-Tung University, Hsinchu, Taiwan. In 2006, he joined the Institute of Computer Science, National Chiao-Tung University. His current research interests include signal processing for wireless communications, multiple-input multiple-output (MIMO) orthogonal frequency-division multiplexing (OFDM) systems, and associated very large-scale integration (VLSI) architectures.

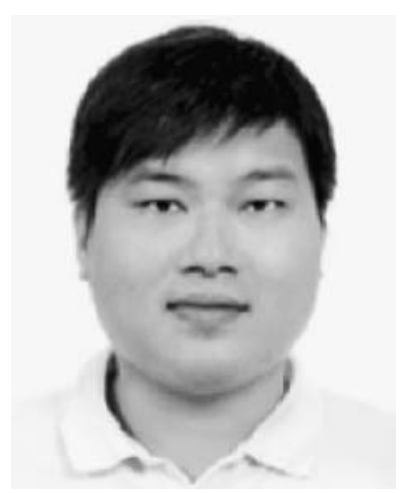

Ta-Yang Juan received the B.S. and M.S. degrees in computer science and information engineering from National Chiao-Tung University, Hsinchu, Taiwan, in 2004 and 2006, respectively, where he is currently working toward the Ph.D. degree in computer science at the Institute of Computer Science. His current research interests include signal processing and channel estimation for MIMO-OFDM communications, and associated very large-scale integration (VLSI) architectures. 


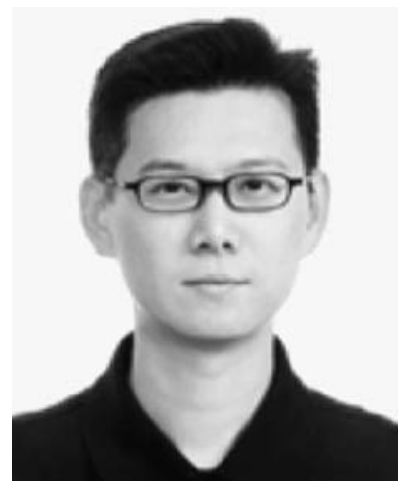

Terng-Yin Hsu (M'07) received the B.S. and M.S. degrees from Feng Chia University, Taichung, Taiwan, in 1993 and 1995, respectively, and the Ph.D. degree from National Chiao-Tung University, Hsinchu, Taiwan, in 1999, all in electronic engineering. In 2003, he joined the Department of Computer Science, National Chiao-Tung University, where he is currently an Assistant Professor. His current research interests include VLSI architectures, wireless communications, multispec transmissions, high-speed networking, analog-like digital circuits, system-on-chip (SoC) design technology, and related application-specific ICs (ASIC) designs.

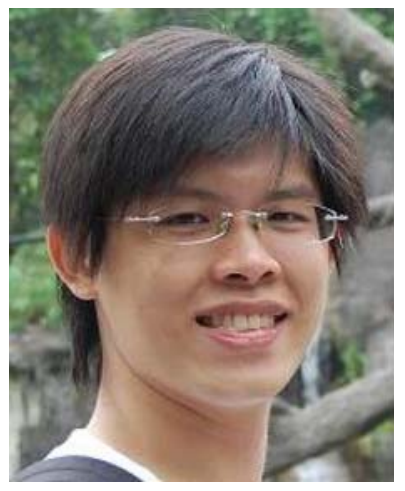

Sheng-Lun Chiou received the B.S. degree in electronic engineering from National Kaohsiung University of Applied Sciences, Kaohsiung, Taiwan, in 2002 and the M.S. degree in electrical engineering from National Cheng Kung University, Tainan, Taiwan, in 2004. He is currently working towards the Ph.D. degree in the Department of Electrical at the National Cheng Kung University, Tainan, Taiwan. His research interests include wireless communication signal processing, estimation and detection theory, information theory, multiple antenna techniques. Since 2008, he worked in Institute for Information Industry (III), Taipei, Taiwan, in the 3GPP LTE area of developing Technical Specifications (TS) and Technical Reports (TR). 